of body fluids ('humoral rheology'). Dr. R. Houwink, of the Rubber-Stichting, Delft, who was also chief secretary of the Congress, spoke on rheology in industry, outlining the main rheological properties important for industry, with special reference to glass, asphaltic bitumen, thermoplastics, thermosetting plastics and paints.

In a short account of the Congress it is impossible to deal with all the contributions to the sectional meetings, numbering between thirty and forty papers; but it can be said that the ground covered was very wide.

There were a number of papers on thixotropy, including one by Sir Charles Goodeve, in which a novel model was described to represent thixotropic and plastic flow. Dr. H. Nitschmann, from the Harvard Medical School, Boston, described interesting experiments on thread-forming liquids, showing the relationship between this property and changes in viscosity with driving pressure. Dr. C. N. Davies, of the London. School of Hygiene and Tropical Medicine, also discussed thread formation of liquids. It was somewhat unfortunate that, in an otherwise admirably arranged programme, Drs. Davies' and Nitschmann's papers were read in different sections almost simultaneously. M. M. Louis (Reuil, France) described a new type of viscometer for industrial use which should have a wide appeal on account of its simplicity of design; and a number of new rheometers were also described for the study of rubber, plastics, printing inks and other materials. Drs. H. de Bruijn and P. G. Meerman, of the Netherlands State Mines, discussed the use of a Stormer viscometer for settling suspensions, and Mr. W. Lethersich, of the Electrical Research Association, the relative merits of compression and rotation instruments for work on dielectrics.

On the theoretical side, turbulence phenomena received considerable attention; Dr. R. Schnurmann, of the Manchester Oil Refining Co., dealt with Reynolds' numbers in solutions of large molecules, and Dr. J. C. Oldroyd (Courtaulds, Ltd., Maidenhead) discussed wall-effects in turbulent flow through pipes. Prof. J. J. Hermans (University of Groningen) gave a summary of his well-known work and that of Prof. P. H. Hermans on swelling of gels, and Prof. W. T. Astbury (Leeds) gave an account of $\mathrm{X}$-ray and electron microscope studies on myosin and actin.

Of the thirty-eight sectional papers, apart from general lectures, circulated in preprint form before the meeting, no less than twenty were from British rheologists, and, indeed, Great Britain was very well represented at the Congress.

An exhibition of rheological apparatus included instruments from Holland, Great Britain and France. The apparatus was classified in accordance with the way in which the stresses are applied, for example, direct, alternating, etc., whether the stress is distributed homogeneously throughout the material, or inhomogeneously, and whether the rates of shear are constant or variable. There were some sixty instruments grouped in this way. The exhibition was open during most of the Congress, and Dr. R. N. J. Saal gave a short informal address describing the exhibits and their classification.

On the evening of September 23 an informal dinner was held, Prof. H. R. Kruyt presiding. Prof. Kruyt proposed the health of the delegates, and replies were made on behalf of Great Britain by Dr. G. W. Scott Blair, of the Continental countries by
Prof. C. Sadron and of the United States by Dr. A. Voet.

Following the Congress, many delegates took part in a three-day trip by touring car to Arnhem and the State Mines in the Province of Limburg. On September 25 visits were paid to the General Rayon Union, to the Staple Fibre Factory of the A.K.U., to the Netherlands Shipbuilding Experimental Station at Wageningen and to the Central Food Products Research Station. On September 26 there was a visit to the Arnhem Battlefield and on Septem. ber 27 to the Central Experimental Station of State Mines at Treebeck.

The Congress was very well organised, although, in spite of the quite remarkable recovery already made, conditions in Holland are at least as difficult as they are in Britain. The Dutch organising committee must have worked extremely hard in preparing the Congress, and the unfailing kindness and help which we received from all our Netherlands col. leagues, and especially from Prof. J. M. Burgers (chairman), Dr. R. Houwink (first secretary) and Dr. G. E. Rotgans (organising secretary), will long be remembered. (As Dr. Houwink said at the dinner, Dr. Rotgans turned out to be "not a bad goose, but a very good goose indeed !')

Although in existing circumstances it was felt to be unwise to fix a date and place for the Second Congress, it was the general feeling both in the Congress itself and within the International Joint Committee that congresses of this kind should be held about every four years, and the hope was expressed that the Joint Committee should recom. mend the calling of a Second Congress in due course.

The Proceedings of the First Congress will be published shortly and will be available at an approximate cost of $£ 28 s$.

G. W. SCOTT BLAIR

\section{NATIONAL RESEARCH COUNCIL OF CANADA ANNUAL REPORT}

$T$

HE thirty-first annual report of the National Research Counoil of Canada (Ottawa) covers the year ended March 31, 1948, and includes the report of the president, Dr. C. J. Mackenzie, together with the financial statement. The total expenditure during the year amounted to just over 6.9 million dollars; almost a further quarter of a million dollars was expended on work carried out at the request of Government Departments and provided for by them, apart from the 7.646 million dollars received in other ways, including parliamentary appropriations of $6 \cdot 351$ million dollars. To cope with the expanding programme, facilities have been extended and the staff now total more than 2,300 , of whom a thousand, half of them scientific workers, are working at the atomic energy project at Chalk River. The operating branch for the production and extraction of isotopes was organised during 1947, and branches of the project are concerned with the problems of operating the low-energy ZEEP and the higherpowered experimental NRX piles and handling their highly radioactive products safely and effectively. Attempts are being made to spread the new techniques and knowledge to the universities and other research institutions in Canada, and thus to foster research in these fields. 
A new Division of Radio and Electrical Engineering has been established and substantial progress made in the applications of radar. In harbour control a nine-inch display with accurate ranging facilities has been added to the original installation at the Naval Signal Station at Camperdown, Nova Scotia, and procedures are being worked out for the use of shore. based radar in the identification and guidance of incoming ships that are not equipped with radar. Trials during the past season have shown that blind navigation of the entrances of Toronto Harbour and identification of every wharf within the Harbour is possible. The practical value of a direct-reading electronic instrument for locating hot joints on power lines has been demonstrated in field tests.

The Division of Physics earried out magnetometer surveys during the latter part of the year in cooperation with the Department of Mines and Resources and with the assistance of the Royal Canadian Air Force. A fundamental investigation has been started on the nature and source of cosmic rays, in particular their relation to other geophysical phenomena such as magnetic storms, and the ionosphere. A high-speed cine-camera capable of operating at a rate of 200,000 frames per second has been designed and built, and a method of geophysical prospecting has been tried in which measurements are made of the depth of overburden by vertical echo-ranging from the surface, and exploration within the bed-rock, with a device which is dropped down a drill-bed. Architectural studies include a series of commercial sound-absorption tests, while equipment has been completed for producing high-intensity sound fields at frequencies from four kilocycles to about 600 kilocycles per second, and a new rod thermostat is being developed for use in railway refrigerator cars. A summer programme of panel-cooling investigations in two experimental houses was undertaken and continued through July and August 1947, while photographic research included work on the aerial camera, the dimensional stability of photographic film bases and the factors affecting the rendering of detail in contact printing.

The organisation of the Pure Chemistry Branch has been completed, and an infra-red spectrometer installed in the section on organic spectrochemistry. Among many problems investigated in the Applied Chemistry Branch of the Division of Chemistry are the lubrication of railway car journal bearings, the correlation of laboratory abrasion tests with actual road tyre tests, the laundry application of dustlaying oils to cotton and wool hospital fabrics, corrosion inhibitors for use in various types of solution and the spreading of oil paints on certain repellent surfaces. A co-operative research with the Noranda Mines, Ltd., promises to develop a method of roasting pyrites for the recovery of elemental sulphur, and the investigation of silver alloys as catalysts for the oxidation of ethylene to ethylene oxide with air has led to the development of highly active stable catalysts. A method has been developed for the rapid determination of low concentrations of carbon monoxide in air.

Much of the work of the aeronautics section of the Division of Mechanical Engineering is devoted to wind-tunnel testing of new aircraft designs for Canadian firms; the low-temperature laboratory continued the flight investigation of aircraft icing, electro-thermal de-icing for wings and propellers and the study of meteorological conditions associated with ice. A snow-cover survey was initiated, in co-operation with the Meteorological Service of the Department of Transport, to obtain data on the type and condition of snow encountered in different parts of Canada, in order to assist in developing snowclearing equipment and in the study of such subjects as aircraft skis. Work continued on the improvement of fuels and lubricants for use at low temperatures, and research was initiated on fuels and combustion in jet engines.

In the Division of Applied Biology, substantial progress was made in research on food preservation and the industrial utilization of agricultural wastes and surpluses. Investigations on oiling, antiseptic and gas treatment of shell eggs have facilitated shipments to Britain, and transport temperatures have been established for a milder and more acceptable bacon. Extensive work has indicated that the Fritz machine for continuous butter production, as designed for German use, cannot consistently produce butter meeting the Canadian legal standard of not more than 16 per cent moisture content. Laboratory studies on new cooling mixtures to provide lower temperatures in refrigerated railways cars gave promising results, and a study has been commenced on the fermentation of cellulose wastes, while that on the fermentation of beet molasses has reached the pilot-plant stage. Work was also commenced on the utilization of straw.

\section{FORTHCOMING EVENTS}

(Meetings marked with an asterisk * are open to the public)

\section{Monday, November 8}

INSTITUTION of POST OFFICE ELECTRICA ENGINEERS (at the Institution of Electrical Engineers, Savoy Place, Victoria Embankment, London, W.C.2), at 5 p.m.-Mr. W M. Bray for Telecommunicaof Supp

Royal Geographical Society (at Kensington Gore, London, S.WOYAL at 5 p.m.-Prof. G. H. J. Daysh: "Development Areas and S.W .7), at 5 p.m.-Prof. "-
the Location of Industry".

\section{Tuesday, November 9}

ROYAL ANTHROPOLOGICAL INSTITUTE (at 21 Bedford Square, London, W.C.1), at 5 p.m.-Mr. A. L. Armstrong and Prof. H. J. Fleure, F.R.S.: "Discovery of a Palæolithic Skull in a Rock Sheiter at Whaley, near Creswell, Derbyshire"

ZOOLOGICAL SOCIETY OF LONDON (at the Zoological Gardens, Regent's Park, London, N.W.8), at 5 p.m.--Scientific Papers.

INSTITUTE OF PHYSICS, ELECTRONICS Group (at 47 Belgrave Square london, S.W.1), at 5.30 p.m.-Mr. P. H. Flanders: "The Physical Properties of Very High Voltage $X$-Rays and Electrons and their Medical Benefit".

INSTITUTION OF Electrical ENGINEERS, Radio SECTION (at Savoy place, Victoria Embankment, London, W.C.2), at 5.30 p.m.-Continuation of the Discussion on "To What Extent does Distortion opened by Mr. P. P. Eckersley).

Sogtraty of Chrmical InDUSTry, Chemicat Enginegring GrodP (at the Geological Society, Burlington House, Piccadilly, Iondon, (at the Geological Society, Burlington House, Piccadilly,
W.1), at 5.30 p.m.-Mr. A.D. Davidson: "Heat Transfer"

ILLUMINATING ENGINERRING SociETy (at the E.L.M.A. Lighting Service Bureau, 2 Savoy Hill, London, W.C.2), at 6 p.m.-Dr. J. W. Mitchell: "High Speed Photography".

INSTTTUTION OF MECHANICAL ENGINEERS, AUTOMOBLLE DIVISION (at Storey's Gate, St. James's Park, London, S.W.1), at 6 p.m.Discussion on "Rubber as a Stress-Carrying S. W. Marsh).

SIR HALLEY STEWART TRUST LECTURE (at the Memorial Hall, SIR HALLEY STEWART TRUST LEOTURE (at the Memorial Hall,
Frringdon Street, London, E.C.4), at 6 p.m.-Mr. R. F. Harrod "Farringdon Street, London, E.C.4), at 6 p.m.-Mr. R. F. Harrod, "The Atomic Age-The Economic Repercussions of Atomic Power": MANCHESTER GEOGRAPHICAL SoCIETY (in the Geographical Hall, St. Mary's Parsonage, Manchester), at 6.30

TRXTI Texin : Th 7 m containing Textile Effluent"

Wednesday, November 10 PHYSICAL SocietY, Colour Group (at the E.L.M.A. Lighting Service
Bureau, 2 Savoy Hill, London, W.C.2), at 3.30 p.m.-Scientifle Papers. 